\title{
A known pathogenic variant in the essential mitochondrial translation gene RMND1 causes a Perrault-like syndrome with renal defects
}

\section{To the Editor:}

Perrault syndrome is a rare autosomal recessive condition characterized by sensorineural hearing loss (SNHL) in both sexes and primary ovarian insufficiency (POI) in 46, XX females. Additional phenotypes, especially progressive neurological features affect some individuals. Six genes have been identified as causative for Perrault syndrome: HSD17B4, HARS2, LARS2, CLPP, C10orf2 and ERAL1, the latter 5 of which function in mitochondrial translation. ${ }^{1,2}$ As many cases of Perrault syndrome are unresolved at a genetic level it is suggested that additional Perrault genes are undiscovered. ${ }^{1}$

We present a case with the defining clinical features of Perrault syndrome, in addition to renal dysfunction and short stature, associated with a known pathogenic variant, RMND1 c.713A>G p.(Asn238Ser). ${ }^{3}$ Patients provided written informed consent in accordance with local regulations. Ethical approval was granted by the National Health Service Ethics Committee (16/WA/0017) and the University of Manchester. The proband is from a non-consanguineous Portuguese family with unaffected parents and 2 unaffected brothers. SNHL was noted at 7 years of age and was moderate to severe at 16 years of age. At 10 years of age short stature, growth hormone deficiency and POI were observed. She also had distal renal tubular acidosis, renal dysfunction has not been previously associated with Perrault syndrome. The proband had 2 measurements of lactic acid with elevated/borderline results; postprandial: $2.01 \mathrm{mmol} / \mathrm{L}$ (reference: <1.8) and $1.9 \mathrm{mmol} / \mathrm{L}$ (reference: 0.5-1.6). A full neurological evaluation, including electromyography, was performed with no neurological phenotype noted. The proband attends a mainstream school and undertakes age appropriate work with no additional assistance. No additional members of the family reported any health problems.

Whole exome sequencing was performed on the proband (SureSelect Human All Exon V5 Panel [Agilent, Santa Clara, California] and HiSeq 2500 [Illumina, San Diego, California]). ${ }^{1}$ No putative pathogenic variants were identified in known Perrault syndrome genes. We classified the homozygous known pathogenic variant, RMND1 c.713A>G p.(Asn238Ser) (NM_017909) as the likely cause of the phenotype in the proband. The variant segregated with the phenotype (Sanger sequencing using ABI big Dye v3.1 technology [ThermoFisher
Scientific Inc.]); both parents and both unaffected siblings were heterozygous.

RMND1 has been proposed to tether the mitoribosome to the mitochondrial inner matrix. ${ }^{4}$ Variants in RMND1 are associated with a wide phenotypic range including SNHL, hypotonia, developmental delay, lactic academia and renal dysfunction. Many patients have a defect in mitochondrial translation. ${ }^{3}$

The variant RMND1 c.713A>G has been observed as homozygous in 2 unrelated families (Table 1). In both families SNHL, developmental delay, hypotonia and peripheral spasticity were observed, one patient had renal dysfunction. All 3 affected individuals are prepubertal, including 1 affected female. ${ }^{3}$ The phenotypic range associated with this RMND1 variant suggests modifying factors, which may be components of the mitochondrial translation pathway.

POI has not been previously associated with variants in RMND1. In most reported cases of RMND1-related disorders, patients have been of pre-pubertal age so POI may not have yet become apparent. ${ }^{3}$ In 2 affected sisters, aged 17 and 14 years, with the RMND1 c.713A>G variant compound heterozygous with another variant, the absence or presence of POI was not commented upon. ${ }^{3,5}$ This may indicate that $\mathrm{POI}$ is not a feature of all cases of RMND1-associated mitochondrial dysfunction.

We suggest that patients with Perrault syndrome are screened for variants in RMND1 alongside the known Perrault syndrome genes. Renal phenotypes in women with Perrault syndrome features may indicate the causative variant is in RMND1 but the absence of renal dysfunction should not preclude RMND1 screening. We also suggest that POI may be an unrecognized feature of RMND1-related mitochondrial dysfunction and female patients should be monitored for POI.

\section{ACKNOWLEDGEMENTS}

This work was supported by Action on Hearing Loss (S35), Action Medical Research (GN2484) and NIHR Manchester BRC. We would like to thank the family for their participation. The study sponsor had no role in any aspect of the report. 
TABLE 1 Clinical features of individuals homozygous for the variant RMND1 c.713A>G p.(Asn238Ser)

\begin{tabular}{|c|c|c|c|c|}
\hline Individual ID & 4.1 & 4.2 & 5 & II-1 \\
\hline Reference & 3 & & & This report \\
\hline Ethnicity & Caucasian & Caucasian & Caucasian, Native American & Caucasian (Portuguese) \\
\hline Sex & M & M & $\mathrm{F}$ & $\mathrm{F}$ \\
\hline Onset (y) & 0.5 & Birth & Birth & 7 \\
\hline $\begin{array}{l}\text { Age (y) at last } \\
\text { assessment }\end{array}$ & 8 & 6 & 9 & 16 \\
\hline SNHL & Bilateral SNHL & Bilateral SNHL & $\begin{array}{l}\text { Congenital bilateral } \\
\text { progressive SNHL, mid to } \\
\text { high frequencies }\end{array}$ & Bilateral progressive moderate/severe SNHL \\
\hline $\begin{array}{l}\text { Gonadal } \\
\text { dysfunction }\end{array}$ & NR & NR & NR & $\begin{array}{l}\text { Ovarian atrophy and hypergonadotropic } \\
\text { hypogonadism }\end{array}$ \\
\hline $\begin{array}{l}\text { Renal } \\
\text { dysfunction }\end{array}$ & $\mathrm{N}$ & $\mathrm{N}$ & $\begin{array}{l}\text { Cystic dysplasia, possible renal } \\
\text { tubular acidosis, end stage } \\
\text { renal failure, renal } \\
\text { transplant }\end{array}$ & $\begin{array}{l}\text { Distal renal tubular acidosis with } \\
\text { hyperchloremic metabolic acidosis and a } \\
\text { normal anion gap, uric acid mildly elevated, } \\
\text { low urine citrate levels, normal calcium } \\
\text { levels and a normal renal ultrasound }\end{array}$ \\
\hline $\begin{array}{l}\text { Developmental } \\
\text { delay }\end{array}$ & Y & $\begin{array}{l}\text { Yes with regression } \\
\text { at } 4 \mathrm{y}\end{array}$ & Yes with failure to thrive & $\mathrm{N}$ \\
\hline $\begin{array}{l}\text { Neurological } \\
\text { features }\end{array}$ & Y & Y & $\mathrm{Y}$ & $\mathrm{N}$ \\
\hline Tone & $\begin{array}{l}\text { Central hypotonia and } \\
\text { peripheral spasticity }\end{array}$ & $\begin{array}{l}\text { Central hypotonia } \\
\text { and peripheral } \\
\text { spasticity }\end{array}$ & $\begin{array}{l}\text { Central hypotonia and } \\
\text { peripheral spasticity }\end{array}$ & Normal \\
\hline Epilepsy & Febrile seizures & Febrile seizures & Y & $\mathrm{N}$ \\
\hline MRI & $\begin{array}{l}\text { Leukoencephalopathy } \\
\text { temporal lobe cyst }\end{array}$ & NR & $\begin{array}{l}\text { Cerebral atrophy and white } \\
\text { matter changes }\end{array}$ & Normal (spectroscopy not performed) \\
\hline $\begin{array}{l}\text { Additional } \\
\text { features }\end{array}$ & NR & $\begin{array}{l}\text { Torticollis and } \\
\text { plagiocephaly }\end{array}$ & $\begin{array}{l}\text { Microcephaly, hypertension, } \\
\text { mild ventricular } \\
\text { hypertrophy }\end{array}$ & $\begin{array}{l}\text { Growth hormone deficiency, autoimmune } \\
\text { thrombocytopenia, non-immune } \\
\text { hypothyroidism, femoral epiphysiolysis } \\
\text { (13 y of age), ECG normal }\end{array}$ \\
\hline
\end{tabular}

Abbreviations: ECG, electrocardiogram; F, female; M, male; MRI, magnetic resonance imaging; N, no; NR, not recorded; SNHL, sensorineural hearing loss; $\mathrm{Y}$, yes.

\section{Conflict of interest}

The authors declare no conflicts of interest.

\section{ORCID}

L.A.M. Demain (iD http://orcid.org/0000-0001-8694-7710

L.A.M. Demain, ${ }^{1,2}$ (D) D. Antunes, ${ }^{3}$ J. O'Sullivan, ${ }^{1,2}$ S.S. Bhaskhar, ${ }^{1,2}$

R.T. O'Keefe, ${ }^{4}$ and W.G. Newman, ${ }^{1,2}$

${ }^{1}$ Division of Evolution and Genomic Sciences, Faculty of Biology,

Medicine and Health, School of Biological Sciences, University of

Manchester, Manchester, UK

${ }^{2}$ Manchester Centre for Genomic Medicine, Manchester University NHS

Foundation Trust, Manchester, UK

${ }^{3}$ Medical Genetics Department, Hospital de Dona Estefânia, Centro

Hospitalar Lisboa Central, Lisbon, Portugal

${ }^{4}$ Division of Cellular and Molecular Function, Faculty of Biology,

Medicine and Health, University of Manchester, Manchester, UK

Correspondence

Dr William G. Newman, MD, PhD, Manchester Centre for Genomic
Medicine, University of Manchester, 6th Floor, St Mary's Hospital, Oxford Road, Manchester M13 9WL, UK. Email: william.newman@manchester.ac.uk DOI 10.1111/cge.13255

\section{REFERENCES}

1. Demain LA, Urquhart JE, O'Sullivan J, et al. Expanding the genotypic spectrum of Perrault syndrome. Clin Genet. 2017;91:302-312.

2. Chatzispyrou IA, Alders $M$, Guerrero-Castillo $S$, et al. A homozygous missense mutation in ERAL1, encoding a mitochondrial rRNA chaperone, causes Perrault syndrome. Hum Mol Genet. 2017;26: 2541-2550.

3. $\mathrm{Ng}$ YS, Alston $\mathrm{CL}$, Diodato $\mathrm{D}$, et al. The clinical, biochemical and genetic features associated with RMND1-related mitochondrial disease. J Med Genet. 2016;53:768-775.

4. Janer A, van Karnebeek CD, Sasarman F, et al. RMND1 deficiency associated with neonatal lactic acidosis, infantile onset renal failure, deafness, and multiorgan involvement. Eur J Hum Genet. 2015;23: 1301-1307.

5. Ravn K, Neland M, Wibrand F, Duno M, Ostergaard E. Hearing impairment and renal failure associated with RMND1 mutations. Am J Med Genet A. 2016;170A:142-147. 